\title{
A comparison of pollen extraction methods: confirmation of dense-media separation as a reliable method of pollen preparation
}

DOI:

10.1002/jqs.2886

\section{Document Version}

Accepted author manuscript

Link to publication record in Manchester Research Explorer

Citation for published version (APA):

Campbell, J., Fletcher, W., Hughes, P., \& Shuttleworth, E. (2016). A comparison of pollen extraction methods: confirmation of dense-media separation as a reliable method of pollen preparation. Journal of Quaternary Science, 31(6), 631-640. https://doi.org/10.1002/jqs.2886

\section{Published in:}

Journal of Quaternary Science

\section{Citing this paper}

Please note that where the full-text provided on Manchester Research Explorer is the Author Accepted Manuscript or Proof version this may differ from the final Published version. If citing, it is advised that you check and use the publisher's definitive version.

\section{General rights}

Copyright and moral rights for the publications made accessible in the Research Explorer are retained by the authors and/or other copyright owners and it is a condition of accessing publications that users recognise and abide by the legal requirements associated with these rights.

\section{Takedown policy}

If you believe that this document breaches copyright please refer to the University of Manchester's Takedown Procedures [http://man.ac.uk/04Y6Bo] or contact uml.scholarlycommunications@manchester.ac.uk providing relevant details, so we can investigate your claim.

\section{OPEN ACCESS}




\section{A comparison of pollen extraction methods: confirmation of dense-media}

separation as a reliable method of pollen preparation

3 Campbell, J.F.E. ${ }^{1}$, Fletcher, W.J. ${ }^{*}$, Hughes, P.D. ${ }^{1}$ and Shuttleworth, E.L. ${ }^{1}$

$4{ }^{1}$ Quaternary Environments and Geoarchaeology, Geography, School of

5 Environment, Education and Development, The University of Manchester, M13 9PL,

6 UK

$7 \quad{ }^{*}$ Corresponding email: will.fletcher@manchester.ac.uk

\section{Running head}

9 Dense-media separation as a reliable method of pollen preparation

10 Abstract

11 Palynology is a crucial proxy for understanding Quaternary environmental change. A 12 range of laboratory preparation techniques has been developed to deal with the 13 extraction of pollen in different sedimentary contexts. Here, we present a comparison 14 of the conventional hydrofluoric acid (HF) method and the dense-media separation 15 method using sodium polytungstate (SPT). We examine pollen, non-pollen 16 palynomorphs (NPPs) and microcharcoal by undertaking parallel preparation and counting of thirty paired samples from three sites in the Middle Atlas Mountains, Morocco, with contrasting environmental and sedimentary conditions. Differences between microfossil counts are assessed visually and statistically, using ANOVA and linear regression. We observe that the typical offset between counts for the five most common pollen and NPPs produced by the two methods $(\mu=1.6 \%, s d=0.9 \%)$ is considerably smaller than the $95 \%$ uncertainty associated with the standard counting procedure $(\mu=6.8 \%, s d=2.7 \%)$. There is no statistically significant difference associated with the preparation methods, and no significant deviation from a linear relationship between the results obtained by the two methods. There are advantages and disadvantages to both methods in terms of preparation time and visual characteristics. This study confirms that results for pollen, NPPs and microcharcoal obtained by either preparation method can be directly compared. 
Key words: pollen extraction; dense-media separation; hydrofluoric acid; non-pollen palynomorphs; microcharcoal

\section{Introduction}

33 Pollen analysis is a commonly used method for reconstructing past environmental change, and is used widely in Quaternary research (Seppä and Bennett, 2003). Part of the challenge of extracting pollen and other organic microfossils from sediment is separating organic material from siliceous mineral matter of similar size to pollen (silts). The method that is most commonly used involves the dissolution of siliceous material using hydrofluoric acid (HF) (Faegri et al., 2000). An alternative approach is the use of dense-media to separate pollen from the rest of the sediment matrix, such as Thoulet's liquid, $\mathrm{ZnCl}_{2}$, sodium polytungstate (SPT) and lithium heteropolytungstate (LST) (Wood et al., 1996; Nakagawa et al., 1998; van Geel et al., 2011; Caffrey and Horn, 2013). The dense-media separation method is typically used to extract pollen grains from clay-rich or silty sediments, where it may be used to extract very small levels of pollen from highly minerogenic sediments, often where the use of HF has failed to yield substantial quantities of pollen (e.g. Allen et al., 2009; Caffrey and Horn, 2013; Fletcher and Hughes, in press). Dense-media separation can also be used for pollen extraction in more organic-rich material (Nakagawa et al., 1998). Organic-rich samples are often abundant in pollen; however, isolating pollen can be problematic as a result of the difficulty of digesting and removing small organic fragments (Nakagawa et al., 1998). There is evidence to suggest that dense-media separation is highly efficient when preparing organic material for pollen analysis, and can often produce material for analysis that is easier to count than samples that undergo the conventional method using HF (Phipps and Playford, 1984; Forster and Flenley, 1993; Nakagawa et al., 1998; Allen et al., 2009). More recently, dense-media separation has also been adopted as a method in palaeoecology for extraction of non-pollen palynomorphs (NPPs) and microcharcoal analyses (e.g. Turner et al., 2008; van Geel et al., 2011). pollen preparation method - that is, the influence of using HF vs. dense-media 
separation. A pioneering study (Björck et al., 1978) compared the results of pollen analysis via the $\mathrm{HF}$ and $\mathrm{ZnCl}_{2}$ separation methods on clay-rich lake sediments from south-eastern Sweden, and reported good correspondence between the results obtained by the two methods. Nakagawa et al. (1998) examined a set of eleven samples from a range of depositional contexts, and observed compatible results for HF and dense-medium preparations. To date, however, the papers that compare the two methods focus solely on pollen analysis, and do not provide comparative records for either NPPs or microcharcoal (e.g. Nakagawa et al., 1998; Caffrey and Horn, 2013). In addition, comparisons so far have used fairly small numbers of paired samples, and there is little statistical support for the findings. Overall, robust evaluation of key methodological stages in microfossil preparation remains relatively rare (cf. Wolfe, 1997; Riding and Kyffin-Hughes, 2004; Mertens et al., 2009), but is critical for understanding the extent to which results from different studies can be considered compatible. This paper aims to test whether dense-media separation using SPT is a reliable method of pollen preparation for both organic and minerogenic sediments. It provides a comparison of thirty paired samples prepared in parallel for both HF and dense-media separation, analysing pollen, NPPs and microcharcoal in the residues.

\section{Research sites}

The three research sites that are used in this investigation are located in the Middle Atlas Mountains, Morocco. The sites lie within $10 \mathrm{~km}$ of each other, close to the transition between the Mediterranean and Saharan climatic zones (Figure 1). The regional climate is semi-arid, and is influenced by the sub-tropical high-pressure belt during the summer, and the Atlantic westerly circulation in the winter (Lamb et al., 1999). The sites are located in carbonate bedrock areas and occur in depressions related to karstic and tectonic processes. Table 1 summarises the key characteristics of each site.

INSERT FIGURE 1 HERE.

The first site is Lake Sidi Ali (Figure 2a). Sitting at 2080 m.a.s.l., Sidi Ali is a permanent, closed waterbody and one of the largest and highest lakes in the Middle 
90 Atlas Mountains. It is located at $33^{\circ} 03^{\prime} \mathrm{N}, 05^{\circ} 00^{\prime} \mathrm{W}$, within a small closed 91 catchment $\left(\sim 14 \mathrm{~km}^{2}\right)$, with a surface area of $2.8 \mathrm{~km}^{2}$ and a water depth of up to $40 \mathrm{~m}$.

92 A 19.56 metre core was extracted using a UWITEC piston corer with a $2 \mathrm{~m}$ core 93 chamber at the deepest part of the lake (full method described in Zielhofer et al., in 94 review). The sediment at Lake Sid Ali is classified as organic silt, averaging 95 approximately $12 \%$ total organic carbon (TOC), and is rich in pollen, with a typical 96 concentration of $2.5 \times 10^{5}$ grains $\mathrm{cm}^{-3}$.

INSERT FIGURE 2 HERE.

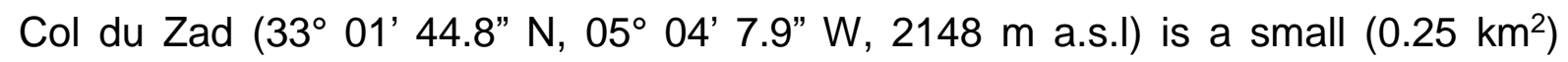
waterlogged depression fed by groundwater springs containing a shallow, seasonal pond (Figure 2b). A $2.2 \mathrm{~m}$ core was collected from the site using a Russian corer. The sedimentary infill is predominantly minerogenic silts and clay, with organic matter content determined by loss-on-ignition typically $14 \%$ (i.e. an estimated $\sim 6-9 \%$ TOC following Veres, 2012). The pollen concentrations are an order of magnitude lower than at Sidi Ali, typically $7.0 \times 10^{4} \mathrm{grains}_{\mathrm{cm}}^{-3}$.

The third site is a shallow lake with a surrounding marshy area (Figure 2c).

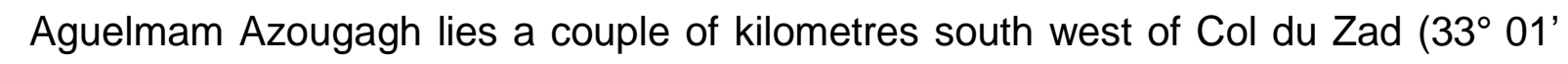
23.2" N, $05^{\circ} 05^{\prime} 29^{\prime \prime}$ W, $2058 \mathrm{~m}$ a.s.I). A $4.4 \mathrm{~m}$ core from the marsh was collected using a combination of Russian corer and gouge auger. The sediment is predominantly minerogenic, but has a moderate organic content throughout the core, averaging $13 \%(\sim 5-9 \%$ TOC), reaching $>30 \%$ (i.e. an estimated $\sim 12-20 \%$ TOC maximum). Typical pollen concentrations are slightly higher than at Col du Zad (9.8 $\mathrm{x}$ $10^{4}$ grains $\mathrm{cm}^{-3}$ ).

These three sites present contrasting environmental conditions, with sediment from a deep lake, a shallow, marshy lake, and a seasonally waterlogged bog. In addition, the three cores contain a range of sediment types, and as a result we have tested our hypotheses on sediments that are organic rich, highly minerogenic, and less minerogenic clays.

\section{Methodology}

\subsection{Pollen preparation}


120 Ten pairs of samples were taken from ten different depths in each core, or thirty

121 pairs in total. A known quantity of exotic marker spores (Lycopodium) was added in 122 tablet form, following a standard approach to allow for estimation of the absolute 123 concentration of palynomorphs (Stockmarr, 1971). Samples were prepared using 124 both the HF method and the dense-media separation method. All samples were 125 prepared in parallel until stage 6 (Figure 3), when half were treated with hydrofluoric 126 acid and the other half from the same depths underwent pollen extraction using the 127 dense-media separation method, with SPT prepared to a density of $1.88-1.91 \mathrm{~g} / \mathrm{cm}^{3}$. 128 The preparation was identical and continued in parallel for the remaining few steps 129 (Figure 3). The detailed preparation protocol is provided in Appendix 1.

\section{INSERT FIGURE 3 HERE}

\section{$131 \quad$ 3.2. Pollen, NPP and charcoal analysis}

132 Full pollen counts were conducted for each of the twenty samples at each site. This 133 involved counting a minimum of 300 terrestrial grains, along with any aquatic grains, 134 spores and NPPs. Pollen taxa were identified primarily using Moore et al. (1991) and 135 Reille (1999), and percentages were calculated against the total land pollen. The 136 taxonomy of NPPs includes a mixture of taxa, some of which are of known biological 137 affinity at the species, genus or family level, while others are known only from 138 microfossils. The taxa identified here are listed as 'type' following the Hugo de Vries $139(\mathrm{HdV})$ Laboratory numbering, and were identified based on the descriptions outlined 140 in various studies, including: van Geel, 1972, 1978; Pals et al., 1980; Kuhry, 1985; 141 van Geel et al., 2003; van Geel and Aptroot, 2006. The abundances of NPPs, 142 aquatics and spores are expressed as a percentage, with the individual spore count 143 included in the pollen sum:

$$
X_{\%}=\frac{N x}{T L P+N x} \times 100
$$

146 Where $\mathrm{X} \%$ is the percentage of the individual NPP taxon, TLP is total land pollen 147 counted and $\mathrm{Nx}$ is the number of NPPs of that taxon counted (Moore et al., 1991). 
148 Microscopic charcoal analysis was conducted using the same slides as the pollen 149 analysis. A sum of 200 charcoal particles and Lycopodium spores was counted in

150 each sample, to reach an accurate estimate of particles for the entire sample, with 151 less than 5\% error (Finsinger and Tinner, 2005). These were split into four size 152 classes: $<20 \mu \mathrm{m}, 20-50 \mu \mathrm{m}, 50-100 \mu \mathrm{m},>100 \mu \mathrm{m}$, measured using a calibrated 153 graticule. Charcoal concentrations are expressed in number of fragments per $\mathrm{cm}^{3}$.

\section{3.3. Statistical analysis}

155 The statistical approach includes three stages: (i) comparison of differences in 156 abundances between the pairs against 95\% confidence limits on the counts, (ii) 157 ANOVA to test for the influence of method on the pollen and NPP abundances, and 158 (iii) a series of linear regressions for individual microfossil taxa/types, including pollen 159 and NPP abundances, charcoal concentrations and Lycopodium counts. The 160 rationale for stage (i) is to evaluate the amplitude of the difference in the counts for 161 main taxa produced by the two methods against counting uncertainty associated with 162 the standard counting method. Stage (ii) tests for the influence of preparation 163 method on the most common pollen and NPP taxon abundances. Stage (iii) models 164 the relationship for individual, significant taxa between the counts produced by each 165 method to test for departure from a predictable linear relationship. Our working 166 hypothesis is there will be no significant difference between the pollen, fungal spore 167 and charcoal counts produced from the paired samples prepared using two different 168 methods: dense-media separation, with SPT, and the conventional method, with HF.

169 All relationships were tested at the $95 \%$ level $(p \leq 0.05)$.

\subsection{1. $95 \%$ confidence limits}

171 When conducting pollen counts, it is understood that any count only provides an 172 estimate of the true values of the population of the sample (Maher, 1972; Faegri et 173 al., 2000). Analysis of confidence limits was performed on the top five most common 174 pollen taxa in terms of average abundance per sample (Cedrus, Cupressaceae, 175 Quercus evergreen type, Quercus deciduous type, Poaceae). These were calculated 176 using the method of nomograms as presented in (Maher, 1972), and implemented in 177 the software Psimpoll (Bennett, 1992). 
179 An analysis of variance (ANOVA) following a general linear model (GLM) approach 180 (Rutherford, 2001) was employed to determine the statistical significance of the 181 influence of two factors (method and taxa), and their interaction (method ${ }^{\star}$ taxa), on 182 pollen and NPP abundance for the major taxa. The ANOVAs were implemented in 183 the software package SPSS. There are two levels for method (HF, SPT) and five 184 levels for pollen taxa (Cedrus, Cupressaceae, Quercus evergreen type, Quercus 185 deciduous type, Poaceae). The test was repeated for NPPs with the same two 186 factors (method, taxa) with five levels for the most common taxa (Type 8a, Sordaria, 187 Type 25, Type 202, Type 303). These two tests were performed separately to 188 independently assess the influence of preparation method on pollen and NPPs, 189 respectively. In each case, the influence of method on the overall dataset of common 190 taxa is of primary interest. Also of interest is the interaction between the factors 191 (method*taxa), which will highlight whether the method factor (i.e. the two 192 preparation methods) has a different influence on specific levels of the second factor 193 (taxa), i.e. a specific influence on the abundances of any of the individual pollen taxa. 194 The significance of the results is evaluated with respect to the $p$ value and $\omega^{2}$, a 195 measure of the effect size (Rutherford, 2001).

\subsubsection{Assessment of one-on-one relationship by linear regression}

197 An assessment of the relationship between the two methods was then conducted using a linear regression approach, adapted from the assessment carried out for geochemical data obtained by different measurement techniques (assessing accuracy of field portable X-ray fluorescence measurements), by Kilbride et al. (2006) and Shuttleworth et al. (2014). Linear regression was performed on all pollen and NPP taxa occurring at least once at $>5 \%$ abundance, as well as on total microcharcoal concentrations and Lycopodium counts. Rare taxa are excluded because the abundance of zero values makes them unsuitable for this analysis. The analyses are summarised in Figure 4.

206 For each taxon (pollen and NPP), least-squares linear regression is undertaken, 207 where: 
$209 Y$ is the percentage abundance from the SPT preparation (SPT\%), $x$ is the 210 percentage abundance from the paired HF preparation (HF\%), $c$ is the y-intercept of

211 the regression line, $m$ is the slope and $\varepsilon$ is the error term. Following regression, the 212 distribution of residuals was checked for normality, and a classification procedure

213 followed relating to the nature of the relationship between SPT\% and HF\%. In this 214 case, where $\mathrm{R}^{2}>0.85$ and $c=0$ and $m=1$ (within $5 \%$ confidence level), then the 215 relationship $y=x$ is accepted and the two datasets are considered statistically 216 similar, i.e. displaying a definitive, linear, one-on-one relationship. Where $\mathrm{R}^{2}$ is 217 between 0.7 and 0.85 , or $\mathrm{R}^{2}$ is $>0.85$ and either $c=0$ and $m=1$ is not accepted at 218 the 5\% level, then either the relationship $y=m x+c$ or $y=m x$ is accepted, 219 respectively, such that the two datasets are statistically different in terms of either the 220 slope or the intercept, i.e. displaying a linear but not strictly one-on-one relationship 221 (quantitative data). Where $\mathrm{R}^{2}<0.7$, the relationship between $\mathrm{SPT} \%$ and $\mathrm{HF} \%$ is 222 weakly linear and the data are statistically different (qualitative data).

\section{Results}

\subsection{Comparison of the total pollen counts, fungi and charcoal}

226 The microfossil data from each core is presented in Figures $4 a, b$ and c. Visual comparison of the HF and SPT results indicates that abundances are very similar for the pairs of samples prepared using the two techniques at all three sites. Overall, the differences in abundances are small, both for common and rare taxa, with a maximum difference in any single sample of $5 \%$ (Cedrus). While the counts are not identical, a perfect agreement would not be expected - even performing two counts from the exact same sample would not yield identical results. There does not appear to be a consistent offset (i.e. consistent over- or under-representation of particular taxa), $24.6 \%$ of pairs show higher values following SPT treatment while $24.1 \%$ of pairs show higher values following HF. We can see that this is also the case when looking at the NPP abundances and the charcoal concentration. 


\section{2. $95 \%$ confidence intervals}

239 The 95\% confidence intervals of the five most common pollen taxa were calculated

240 for each of the sixty counts (Cedrus, Quercus evergreen type, Quercus deciduous 241 type, Poaceae, Cupressaceae). For every single sample, the HF count falls within 242 the confidence interval of the SPT count, and vice versa (Appendix 2). The average 243 difference between the upper and lower limits of the 95\% confidence intervals were 244 calculated, and these were as follows: Cedrus 9.6\%, Quercus evergreen type 8.1\%, 245 Quercus deciduous type 4.7\%, Poaceae 6.6\%, Cupressaceae 5.1\%. These values 246 clearly indicate that there is a fairly wide uncertainty associated with the standard 247 counting procedure (300 pollen grain main sum), and that the confidence intervals 248 are greater than the absolute differences associated with the two preparation method 249 (averages: Cedrus 2.6\%, Quercus evergreen type 1.7\%, Quercus deciduous type $2501.1 \%$, Poaceae 1.5\%, Cupressaceae 1.1\%). Overall, the typical offset between 251 counts for the five most common pollen and NPPs produced by the two methods $252(\mu=1.6 \%, s d=0.9 \%)$ is considerably smaller than the $95 \%$ uncertainty associated with

253 the standard counting procedure $(\mu=6.8 \%, \mathrm{sd}=2.7 \%)$.

\subsection{ANOVA}

The results of the ANOVA for major pollen taxa and NPPs are given in Table 2 and Table 3, respectively. For both tests, there is no significant influence of the method factor on the pollen or NPP abundances (95\% confidence level). As would be expected, there are significant effects of the second factor (taxa) on pollen/NPP abundances, as some of the taxa are simply more common than others. Importantly, however, no statistically significant interaction between the two factors (method*taxa) is observed, i.e. no patterns of difference between taxa can be related to the influence of method. For pollen (NPPs), the $\omega^{2}$ indicates that $31 \%(26 \%)$ of the variation between the samples can be associated with the taxa; the other $69 \%(74 \%)$ is unaccounted for by the test. This large unaccounted proportion of the variance reflects inter-sample differences related to palaeoecological changes at the sites. 
266 Effectively, the method and the interaction of method and taxa are responsible for none of the variation in abundances of major pollen and NPP types.

\subsection{Linear regression}

270 Table 4 summarises the results of the linear regression analysis, and Figure 5 271 displays examples of the linear regression models for several taxa. The $\mathrm{R}^{2}$ values 272 are all above 0.85 . This shows that the strength of linear association between the 273 two methods is very high. The quality level shows that in all but one case, we can 274 accept that $y=x$ within the $5 \%$ confidence level, i.e. that both methods of pollen 275 preparation yield statistically similar results. Values for one pollen taxon, 276 Caryophyllaceae, conform strongly to a linear relationship $\left(R^{2}=0.981\right)$ but the one-

277 on-one line falls narrowly outside the $5 \%$ confidence limits of the best fit model, with 278 slightly higher values in the SPT preparations. However, average abundance of this 279 taxon is low (0.7\%) and therefore the model will be sensitive to small differences in 280 raw counts. Overall, the regression analysis highlights how closely the values for 281 pollen and NPP abundances, and microcharcoal concentrations, conform to a one282 to-one, linear relationship, underlining a negligible influence of HF vs SPT treatment 283 during the preparation stages. It is also important to note that counts for the exotic 284 marker spore, Lycopodium, strongly conform to the highest category of definitive 285 linear relationship (Table 4).

\section{Discussion}

289 So, is the use of the dense-media separation a reliable method for preparing samples for pollen, fungal spore and charcoal analysis? The results of all analyses here clearly indicate that there is no significant difference between the results produced by both methods. We have compared microfossils with a range of different morphologies: charcoal, NPPs, and a variety of pollen types, including conifer taxa (e.g. Cedrus), which have substantial air bladders (sacci) that might be anticipated to 
295 influence the density of the grain. Cedrus is a particularly crucial taxon in Middle 296 Atlas Holocene pollen records, as the nature of its glacial and Holocene 297 biogeographical history is of keen regional interest (Lamb and van der Kaars, 1995; 298 Cheddadi et al., 1998; Lamb et al., 1999). Despite having the largest differences in 299 the results presented, the differences between the parallel Cedrus abundances are 300 still very small, and are seen to be insignificant (Figure 5); the results indicate that 301 the use of the dense-media separation method has no impact on these samples and 302 the results that are produced. Our findings confirm previous conclusions drawn by 303 Björck et al. (1978) and Nakagawa et al. (1998), that pollen abundances are not 304 altered when samples undergo dense-media separation, and furthermore extend this 305 finding to other microfossil components of the samples (microcharcoal and NPPs). 306 The comparable results obtained for the Lycopodium marker spores are also 307 important because they confirm that concentration values calculated on the basis of 308 the ratio of pollen or NPPs to Lycopodium will not be significantly affected by the 309 choice of HF or dense media separation at the preparation stage.

310 The visual and statistical results show that there is no bias towards larger or smaller 311 pollen grains when using the dense-media method - this would be highlighted 312 clearly, for example, in significant deviation in slope or intercept in the linear models, 313 which we do not observe. We analysed a range of sizes and morphologies, including 314 Cedrus - a large, bisaccate pollen grain, typically 60-80 $\mu \mathrm{m}$ longest dimension - and

315 Quercus evergreen - typically much smaller, with $<25 \mu \mathrm{m}$ longest dimension. The 316 variation that does occur appears essentially random - that is, there is not typically 317 more of one taxon occurring in samples prepared using SPT rather than HF (or vice 318 versa). Overall, statistically similar abundances are obtained from both methods, 319 confirming that the dense-media separation is a reliable method of preparation.

320 The charcoal results are also of particular interest. Figures $4 a, b$ and $c$ show that 321 there is very little difference between not only the total charcoal concentrations, but 322 also the concentrations of the different size categories. This indicates that, while 323 some of the charcoal may become fragmented during the pollen preparation 324 process, the same level of fragmentation occurs regardless of the method used. 
325 Where fragmentation is of critical concern, other preparation protocols aiming to 326 reduce the handling of the sample should be considered (e.g. Rhodes, 1998; Turner 327 et al., 2008). Nevertheless, our findings suggest that dense-media separation does 328 not preclude comparison of size class results as compared to samples prepared with 329 the HF technique.

330 The results of these visual and statistical analyses therefore show that records 331 produced using either preparation technique (i.e. dense-media separation or HF), 332 can be directly compared. This finding is crucial, for example, for the comparison of 333 Late Quaternary Moroccan vegetation records. Previous researchers have used both 334 techniques; the majority of these Moroccan vegetation studies prepared pollen samples using HF (Lamb et al., 1989, 1991, 1999; Lamb and van der Kaars, 1995; McGregor et al., 2009; Rhoujjati et al., 2010; Amami et al., 2013; Muller et al., 2014), however several recent studies prepared samples using dense-media separation protocols (Zapata et al., 2013; el Bait et al., 2014; Bell and Fletcher, 2016; Fletcher and Hughes, in press). In a region that is receiving an increasing amount of interest, particularly regarding Holocene environmental change, the knowledge that these records are directly comparable enables us to begin to accurately study biogeographical changes across the region, and how the nature and timing of environmental and vegetation shifts varied at a regional scale.

Despite the statistical similarity of the microfossil content, visual characteristics of the residues are notably different between the HF and SPT approaches. As noted by Nakagawa et al. (1998), pollen samples prepared using the dense-media separation method are substantially cleaner and more efficient for counting. When reviewing the palaeoenvironmental context of Late-glacial woolly mammoth discoveries, Allen et al. (2009) had to re-prepare their samples for pollen analysis using the dense-media separation method after insufficient results were achieved using the conventional method (using HF). They too found the dense-media separation provided much more efficient material for counting. Figure 6 shows photographs of pollen slides used in this investigation. We draw similar conclusions to those of Nakagawa et al. (1998) and Allen et al. (2009). The dense-media separation samples generated much cleaner slides; the majority of material was in fact pollen grains, NPPs and charcoal, and there was a much smaller amount of excess organic debris on the slides. As a 
result of these cleaner, clearer slides, the NPP and pollen grains were much easier

358 to identify, and measuring the size of the charcoal grains was more accurate. In

359 addition, the slides were much quicker to count, as there was less detrital material, 360 meaning that a greater number of slides could be counted in the same period of 361 time. Similar advantages of SPT have been reported for microinvertebrate 362 preparation techniques (Mitchell and Heckert, 2010).

\section{INSERT FIGURE 6 HERE}

364 An interesting point to note is that there were high levels of other organic matter in the HF samples, but much less in the dense-media separation samples. Both sets of samples were subjected to the same preparation, other than stage 6. HF treatment removes siliceous material, while the removal of humic material from the samples occurs at stage 3, using potassium hydroxide (Faegri et al., 2000). This suggests that during dense-media separation, some dense organic fragments that have not already been destroyed sink to the bottom of the centrifuge tube, and are not transferred along with the pollen grains after dense-media separation has been carried out. Microscopic observation of the heavy residue confirms that there is organic material in the dense fraction settling at 1.88-1.91 $\mathrm{g} / \mathrm{cm}^{3}$, including compact, angular unidentifiable organic fragments, as well as rare pollen grains. Also, some very low density organic matter may be further separated from the main pollen residue at the end of the density separation, when the density is lowered to around $1.15-1.2 \mathrm{~g} / \mathrm{cm}^{3}$ (typically the lowest achievable density without resorting to partitioning the sample across multiple centrifuge tubes). Overall, while the exact reasons are not fully known, the density separation procedure appears to concentrate microfossils with respect to other organic detritus. This concentration effect is capitalised upon, for example, in the preparation of pollen concentrates for radiocarbon dating (Vandergoes and Prior, 2003).

In addition to the clarity of the slides, we also evaluated a range of other advantages and disadvantages of each method. Typically, the HF method has a quicker preparation time than the dense-media separation method when pre-preparation time is taken into account (i.e. preparation of the solution to appropriate density), and time for the samples to settle (not strictly required but makes the decantation easier;

388 Appendix 1). However, due to the cleaner slides, counting and analysis is reduced 
389 when using the dense-media method. The health and safety risks of working with HF 390 are considerable; an HF approved lab is needed, HF-specific training and 391 supervision of the analyst, and suitable personal safety equipment and first aid protocols. Initial per sample costs are typically much higher when using SPT $(\sim £ 5$, as

393 opposed to $\sim £ 0.18$ for HF), although the used SPT can be recovered, filtered and 394 recycled. Other heavy liquids are much cheaper and offer similar performance at costs comparable to HF; however, SPT (and LST) is a non-toxic liquid, and is therefore preferable for routine use over Thoulet's liquid and $\mathrm{ZnCl}_{2}$ (Munsterman and

397 Kerstholt, 1996). The removal of clays and breakdown products of alkali digestion by conducting between six and twenty (in this case, sometimes more) water washes, vastly improved the quality of the samples. Although removal of clays is most critical for density separation (as highlighted by Nakagawa et al., 1998), it is also beneficial for maximising efficiency of the HF stage. It is therefore crucial to spend sufficient time on this stage, depending on the clay content of the samples. Micro-sieving (e.g. $5 \mu \mathrm{m}$ mesh) as an alternative could be considered for further evaluation at this stage. While these advantages and disadvantages may all be important in different laboratory settings, the decisive factor when deciding which method to use is likely to be the sediment type, with specifically either strongly minerogenic, or, very organicrich sediment standing to benefit particularly from the use of dense media.

408 The results of this investigation support an additional degree of flexibility for researchers in terms of choice of preparation procedure. The dense-media separation method may be applied to specific stratigraphic sections within a sediment core, for example a very minerogenic layer, where pollen extraction may prove difficult with HF. Interpretation of the results in this case will need to be approached with caution, as other taphonomic factors (e.g. changes in transport vectors and pollen source areas, pollen preservation, etc.) may influence the nature of the microfossil assemblages; however, the application of dense-media separation does not introduce taphonomic bias in the results.

\section{Conclusions}


419 The aim of this investigation was to test if dense-media separation is an accurate 420 method for microfossil (pollen, NPPs, microcharcoal) preparation, and then compare 421 its efficiency to the standard preparation method. Our results indicate that the dense422 media separation does not introduce any bias in the microfossil counts as compared 423 with HF preparation. Offsets between the comparison counts are typically small $424(\mu=1.6 \%, s d=0.9 \%)$, and considerably less than the $95 \%$ confidence intervals associated with a main counting sum of 300 terrestrial pollen. The ANOVAs indicate that no significant difference between the samples is attributed to the preparation method. The linear regression models further highlight that there is a strong one-onone linear relationship between results from the two methods. For all common taxa (occurring at least once at an abundance $>5 \%$ ) except one relatively rare taxon

430 (Caryophyllaceae), it can be accepted that $y=x$, that is that the two methods yield statistically similar results. There is no evidence in this investigation to suggest that SPT has any effect on the composition of microfossil assemblages within the samples. The results also showed that the use of dense-media separation was effective across a range of depositional contexts in the Middle Atlas, Morocco, including a deep, permanent lake, a seasonally waterlogged pond, and a marsh. While we chose to test multiple samples from across the depth range of each of the three sites, future methodological tests in palynology could use the standard sample method suggested by Nakagawa et al. (2013), thus allowing for similarly rigorous statistical evaluation with replication of results while minimising loss of core material.

440 In terms of wider advantages and disadvantages, dense-media separation 441 preparation may slightly increase the overall preparation time and laboratory costs due to allowing the samples to settle, and because the SPT medium is expensive 443 (but can be recycled). However, the health and safety risks are greatly reduced compared with HF. In addition, the dense-media separation method leads to cleaner slides that maximise counting efficiency. In summary, dense-media separation is as effective a preparation method as the conventional method, using HF, and the methods produce results that are directly comparable.

\section{Acknowledgements}


449 We would like to thank the School of Environment, Education and Development at

450 The University of Manchester for the provision of The Research Scholar Award, to

451 J.F.E. Campbell. We would also like to thank Benjamin Bell and Carol Campbell for 452 their assistance in the field, and John Moore and Jonathan Yarwood for their 453 assistance in the laboratory. We are also grateful to Christoph Zielhofer (Leipzig 454 University) for providing material for analysis from Lake Sidi Ali. Finally, we would 455 like to thank the two anonymous reviewers for their useful comments on the 456 manuscript.

\section{References}

459 Allen JRM, Scourse JD, Hall AR, Coope GR. 2009. Palaeoenvironmental context of 460 the Late-glacial woolly mammoth (Mammuthus primigenius) discoveries at 461 Condover, Shropshire, UK. Geological Journal 44: 414-446.

462 Amami B, Rhazi L, Chaibi M, Fauquette S, Ougougdal MA, Charif A, Ridaoui M, 463 Bouahim S, Grillas P, Muller SD. 2013. Late Quaternary history of a Mediterranean 464 temporary pool from western Morocco, based on sedimentological and palynological evidence. Palaeogeography, Palaeoclimatology, Palaeoecology 392: 281-292. el Bait MN, Rhoujjati A, Eynaud F, Benkaddour A, Dezileau L, Wainer K, Goslar T, Khater C, Tabel J, Cheddadi R. 2014. An 18 000-year pollen and sedimentary record from the cedar forests of the Middle Atlas, Morocco. Journal of Quaternary Science 29: $423-432$.

470 Bell BA, Fletcher WJ. 2016. Modern surface pollen assemblages from the Middle and High Atlas, Morocco: insights into pollen representation and transport. Grana: 116.

473 Bennett K. 1992. PSIMPOLL: a quickBASIC program that generates PostScript page 474 description files of pollen diagrams. INQUA Commission for the study of the

475 Holocene: working group on data handling methods newsletter 8: 11-12.

476 Björck S, Persson T, Kristersson I. 1978. Comparison of two concentration methods 477 for pollen in minerogenic sediments. Geologiska Föreningen i Stockholm 
479 Caffrey MA, Horn SP. 2013. The use of lithium heteropolytungstate in the heavy

480 liquid separation of samples which are sparse in pollen. Palynology 37: 143-150.

481 Faegri K, Krzywinski K, Kaland PE. 2000. Textbook of Pollen Analysis. Blackburn.

482 Finsinger W, Tinner W. 2005. Minimum count sums for charcoalconcentration

483 estimates in pollen slides: accuracy and potential errors. The Holocene 15: 293-297.

484 Fletcher WJ, Hughes, PD. in press. Anthropogenic triggers for Late Holocene soil 485 erosion in the JebelToubkal, High Atlas, Morocco. Catena.

486 doi:10.1016/j.catena.2016.03.025

487 Forster M, Flenley JR. 1993. Pollen purification and fractionation by equilibrium 488 density gradient centrifugation. Palynology 17: 137-155.

489 Kilbride C, Poole J, Hutchings TR. 2006. A comparison of $\mathrm{Cu}, \mathrm{Pb}, \mathrm{As}, \mathrm{Cd}, \mathrm{Zn}, \mathrm{Fe}, \mathrm{Ni}$ 490 and Mn determined by acid extraction/ICP-OES and ex situ field portable X-ray 491 fluorescence analyses. Environmental Pollution 143: 16-23.

492 Kuhry P. 1985. Transgression of a raised bog across a coversand ridge originally 493 covered with an oak-lime forest. Review of Palaeobotany and Palynology 44: 303494353.

495 Lamb H, Roberts N, Leng M, Barker P, Benkaddour A, van der Kaars S. 1999. Lake 496 evolution in a semi-arid montane environment: response to catchment change and 497 hydroclimatic variation. Journal of Paleolimnology 21: 325-343.

498 Lamb H., Eicher U, Switsur VR. 1989. An 18,000-year record of vegetation, lake499 level and climatic change from Tigalmamine, Middle Atlas, Morocco. Journal of 500 Biogeography 16: 65-74.

501 Lamb HF, van der Kaars S. 1995. Vegetational response to Holocene climatic 502 change: pollen and palaeolimnological data from the Middle Atlas, Morocco. The 503 Holocene 5: 400-408.

504 Lamb HF, Damblon F, Maxted RW. 1991. Human impact on the vegetation of the 
505 Middle Atlas, Morocco, during the last 5000 years. Journal of biogeography 18: 519506532.

507 Maher Jr L. 1972. Nomograms for computing 0.95 confidence limits of pollen data.

508 Review of Palaeobotany and Palynology 13: 85-93.

509 McGregor H V., Dupont L, Stuut J-BW, Kuhlmann H. 2009. Vegetation change, 510 goats, and religion: a 2000-year history of land use in southern Morocco. Quaternary

511 Science Reviews 28: 1434-1448.

512 Mertens KN, Verhoeven K, Verleye T, Louwye S, Amorim A, Ribeiro S, Deaf AS, 513 Harding IC, De Schepper S, González C, et al. 2009. Determining the absolute 514 abundance of dinoflagellate cysts in recent marine sediments: The Lycopodium 515 marker-grain method put to the test. Review of Palaeobotany and Palynology 157: 516 238-252.

517 Mitchell J, Heckert A. 2010. The setup, use and efficacy of sodium polytungstate 518 separation methodology with respect to microvertebrate remains. Journal of 519 Paleontological Techniques 7: 1-12.

520 Moore PD, Webb JA, Collinson ME. 1991. Pollen Analysis (Blackwell, Ed). London.

521 Muller SD, Rhazi L, Andrieux B, Bottollier-Curtet M, Fauquette S, Saber E-R, Rifai N, 522 Daoud-Bouattour A. 2014. Vegetation history of the western Rif mountains (NW 523 Morocco): origin, late-Holocene dynamics and human impact. Vegetation History and 524 Archaeobotany.

525 Munsterman, D Kerstholt, S. 1996. Sodium polytungstate, a new non-toxic 526 alternative to bromoform in heavy liquid separation. Review of Palaeobotany and 527 Palynology 91(1): 417-422.

528 Nakagawa T, Brugiapaglia E, Digerfeldt G, Reille M, Beaulieu J-L De, Yasuda Y. 529 1998. Dense-media separation as a more efficient pollen extraction method for use 530 with organic sediment/deposit samples: comparison with the conventional method. 531 Boreas 27: 15-24.

532 Nakagawa T, Kitagawa, H, Payne, R, Tarasov, P, Demske, D. 2013. A standard 
533 sample method for controlling microfossil data precision: A proposal for higher data

534 quality and greater opportunities for collaboration. Quaternary International 290: 239535244.

536 Pals J., Van Geel B, Delfos A. 1980. Paleoecological studies in the Klokkeweel bog 537 near hoogkarspel (prov. of Noord-Holland). Review of Palaeobotany and Palynology 538 30: 371-418.

539 Phipps D, Playford G. 1984. Laboratory techniques for extraction of palynomorphs 540 from sediments. Papers of the Department of Geology, University of Queensland 11: $541 \quad 1-23$.

542 Reille M. 1999. Pollen et Spores d'Europe et d'Afrique du nord. Laboratorie de 543 Botanique Historique et Palynologie: Marseille.

544 Rhodes AN. 1998. A method for the preparation and quantification of microscopic 545 charcoal from terrestrial and lacustrine sediment cores. The Holocene 8: 113-117.

546 Rhoujjati A, Cheddadi R, Taïeb M, Baali A, Ortu E. 2010. Environmental changes 547 over the past c. 29,000 years in the Middle Atlas (Morocco): A record from Lake 548 Ifrah. Journal of Arid Environments 74: 737-745.

549 Riding JB, Kyffin-Hughes JE. 2004. A review of the laboratory preparation on 550 palynomorphs with a description of an effective non-acid technique. Revista 551 Brasileira de Paleontologia 7: 13-44.

552 Rutherford A. 2001. Introducing ANOVA and ANCOVA: a GLM Approach. Sage, 553 London.

554 Seppä H, Bennett KD. 2003. Quaternary pollen analysis: recent progress in 555 palaeoecology and palaeoclimatology. Progress in Physical Geography 27: 548556579.

557 Shuttleworth EL, Evans MG, Hutchinson SM, Rothwell JJ. 2014. Assessment of 558 Lead Contamination in Peatlands Using Field Portable XRF. Water, Air, \& Soil 559 Pollution 225: 1844.

560 Stockmarr J. 1971. Tablets with spores used in absolute pollen analysis. Pollen et 
562 Turner R, Kelly A, Roberts N. 2008. A critical assessment and experimental

563 comparison of microscopic charcoal extraction methods. In Charcoal from the past:

564 cultural and palaeoenvironmental implications. Proceedings of the Third International

565 Meeting of Anthracology, Fiorentino G, , Magri D (eds). BAR International Series,

566 Archaeopress, Oxford, UK: Cavallino (Lecce).

567 van Geel B. 1972. Palynology of a section from the raised peat bog 'Wietmarshcer

568 Moor', with special reference to fungal remains. Acta Botanica Neerlandica 21: 261569284.

570 van Geel B. 1978. A palaeoecological study of holocene peat bog sections in

571 Germany and The Netherlands, based on the analysis of pollen, spores and macro-

572 and microscopic remains of fungi, algae, cormophytes and animals. Review of

573 Palaeobotany and Palynology 25: 1-120.

574 van Geel B, Aptroot A. 2006. Fossil ascomycetes in Quaternary deposits. Nova 575 Hedwigia 82: 313-329.

576 van Geel B, Buurman J, Brinkkemper O, Schelvis J, Aptroot A, van Reenen G, 577 Hakbijl T. 2003. Environmental reconstruction of a Roman Period settlement site in 578 Uitgeest (The Netherlands), with special reference to coprophilous fungi. Journal of 579 Archaeological Science 30: 873-883.

580 van Geel B, Gelorini V, Lyaruu A, Aproot A, Ruchina S, Marchant R, Damste JSS, 581 Verschuren D. 2011. Diversity and ecology of tropical African fungal spores from a 582 25,000-year palaeoenvironmental record in southeastern Kenya. Review of 583 Palaeobotany and Palynology 164: 174-190.

584 Vandergoes MJ, Prior CA. 2003. AMS dating of pollen concentrates-a 585 methodological study of late Quaternary sediments from south Westland, New 586 Zealand. Radiocarbon, 45(3): 479-492.

587 Veres D. 2012. A Comparative Study Between Loss on Ignition and Total Carbon 588 Analysis on Mineralogenic Sediments. Studia UBB, Geologia 47: 171-182. 
589 Wolfe AP. 1997. On diatom concentrations in lake sediments: results from an inter590 laboratory comparison and other tests performed on a uniform sample. Journal of

591 Paleolimnology 18: 261-268.

592 Wood GD, Gabriel AM, Lawson JC. 1996. Palynological techniques_processing and 593 microscopy. In Palynology: Principles and Applications 1, Jansonius J, , McGregor 594 DC (eds). American Association of Stratigraphic Palynologists Foundation; 29-50.

595 Zapata L, Lopez-Saez JA, Ruiz-Alonso M, Linstadter J, Perez-Jorda G, Morales J, 596 Kehl M, Pena-Chocarro L. 2013. Holocene environmental change and human impact 597 in NE Morocco: Palaeobotanical evidence from Ifri Oudadane. The Holocene 23: $598 \quad 1286-1296$.

599 Zielhofer C, Fletcher WJ, Mischke S, De Batist M, Campbell JFE, Joannin S, 600 Tjallingii R, El Hamouti N, Junginger A, Stele A, Bussmann J, Schneider B, Lauer T, 601 Spitzer K, Brachert T, Mikdad A. in revision. Synchronous Atlantic cooling and 602 Western Mediterranean winter 589 rain minima during the last 12,000 years. 603 Quaternary Science Reviews. 
604 Table 1: Characteristics of the study sites.

605

\begin{tabular}{|c|c|c|c|c|c|c|c|}
\hline Site & Site description & Location & $\begin{array}{l}\text { Altitude } \\
\text { (m.a.s.l.) }\end{array}$ & $\begin{array}{l}\text { Basin size } \\
\left(\mathrm{km}^{2}\right)\end{array}$ & $\begin{array}{l}\text { Catchment area } \\
\left(\mathrm{km}^{2}\right)\end{array}$ & $\begin{array}{l}\text { Estimated } \\
\text { TOC (\%) }\end{array}$ & $\begin{array}{l}\text { Average pollen } \\
\text { concentration } \\
\left(\text { grains } \mathrm{cm}^{-3} \text { ) }\right.\end{array}$ \\
\hline Sidi Ali & Permanent lake & $\begin{array}{l}33^{\circ} 03^{\prime} \mathrm{N}, 05^{\circ} \\
00^{\prime} \mathrm{W}\end{array}$ & 2080 & 2.8 & 14 & 12 & $2.5 \times 10^{5}$ \\
\hline Col du Zad & $\begin{array}{l}\text { Waterlogged } \\
\text { depression }\end{array}$ & $\begin{array}{l}33^{\circ} 01^{\prime} 44.8^{\prime \prime} \\
\mathrm{N}, 05^{\circ} 04^{\prime} \\
7.9^{\prime \prime} \mathrm{W}\end{array}$ & 2148 & 0.25 & 1 & $6-9 *$ & $7.0 \times 10^{4}$ \\
\hline $\begin{array}{l}\text { Aguelmam } \\
\text { Azougagh }\end{array}$ & $\begin{array}{l}\text { Shallow lake } \\
\text { and marsh }\end{array}$ & $\begin{array}{l}33^{\circ} 01^{\prime} 23.2^{\prime \prime} \\
N, 05^{\circ} 05^{\prime} 29^{\prime \prime} \\
W\end{array}$ & 2058 & 0.2 & 1.2 & $5-9 *$ & $9.8 \times 10^{4}$ \\
\hline
\end{tabular}

606 *estimated at 0.4-0.7 x LOI (see Veres, 2012)

607

608 
609 Table 2: ANOVA results for pollen.

610

\begin{tabular}{lrr}
\hline Source & \multicolumn{1}{c}{$p$ value } & \multicolumn{1}{c}{$\omega^{2}$} \\
\hline Method & 0.981 & 0.00 \\
Taxa & $<0.001$ & 0.31 \\
Method*taxa & 1.000 & 0.00 \\
Total & & 0.31
\end{tabular}

611 
612 Table 3: ANOVA results for NPPs.

613

\begin{tabular}{lrr}
\hline Source & $p$ value & $\omega^{2}$ \\
\hline Method & 0.939 & 0.00 \\
Taxa & $<0.001$ & 0.26 \\
Method*taxa & 1.000 & 0.00 \\
Total & & 0.26 \\
\hline
\end{tabular}

614

615 
616 Table 4: Linear regression statistics for major pollen and NPP taxa, and 617 microcharcoal concentration

618

\begin{tabular}{|c|c|c|c|c|c|c|c|c|c|}
\hline Taxa & Type & $\begin{array}{l}\text { Average } \\
\%\end{array}$ & $\begin{array}{l}\text { Residuals } \\
\text { normal? }\end{array}$ & $\mathrm{R}^{2}$ & c & $\begin{array}{l}\text { Accept } \\
c=0 ?\end{array}$ & $m$ & $\begin{array}{l}\text { Accept } \\
\mathrm{m}=1 ?\end{array}$ & Quality level \\
\hline Cedrus & Pollen & 27.8 & Yes & 0.973 & 1.452 & Yes & 0.957 & Yes & Definitive $(y=x)$ \\
\hline Botryococcus & Pollen & 19.1 & Yes & 0.999 & -0.068 & Yes & 0.995 & Yes & Definitive $(y=x)$ \\
\hline Quercus evergreen & Pollen & 17.1 & Yes & 0.957 & 0.686 & Yes & 0.955 & Yes & Definitive $(y=x)$ \\
\hline Poaceae & Pollen & 10.1 & Yes & 0.901 & 0.033 & Yes & 0.988 & Yes & Definitive $(y=x)$ \\
\hline Ranunculus & Pollen & 9.4 & Yes & 0.957 & 1.016 & Yes & 1.002 & Yes & Definitive $(y=x)$ \\
\hline Cyperaceae & Pollen & 7.0 & Yes & 0.989 & -0.137 & Yes & 0.999 & Yes & Definitive $(y=x)$ \\
\hline Cupressaceae & Pollen & 6.3 & Yes & 0.952 & 0.498 & Yes & 0.912 & Yes & Definitive $(y=x)$ \\
\hline Quercus deciduous & Pollen & 5.0 & Yes & 0.930 & 0.062 & Yes & 1.062 & Yes & Definitive $(y=x)$ \\
\hline Potamogeton & Pollen & 4.3 & Yes & 0.986 & 0.007 & Yes & 0.982 & Yes & Definitive $(y=x)$ \\
\hline Myriophyllum & Pollen & 3.8 & Yes & 0.946 & 0.276 & Yes & 0.892 & Yes & Definitive $(y=x)$ \\
\hline Asteraceae Lactuceae & Pollen & 2.3 & Yes & 0.898 & 0.0663 & Yes & 0.893 & Yes & Definitive $(y=x)$ \\
\hline Ulex type & Pollen & 2.2 & Yes & 0.851 & 0.328 & Yes & 0.961 & Yes & Definitive $(y=x)$ \\
\hline Artemisia & Pollen & 1.9 & Yes & 0.854 & 0.264 & Yes & 0.872 & Yes & Definitive $(y=x)$ \\
\hline Astragalus danicus & Pollen & 1.8 & Yes & 0.889 & 1.075 & Yes & 0.889 & Yes & Definitive $(y=x)$ \\
\hline Chenopodiaceae & Pollen & 1.7 & Yes & 0.870 & 0.180 & Yes & 0.915 & Yes & Definitive $(y=x)$ \\
\hline Rumex acetosa & Pollen & 1.5 & Yes & 0.974 & 0.989 & Yes & 0.078 & Yes & Definitive $(y=x)$ \\
\hline Ateraceae aster & Pollen & 1.3 & Yes & 0.940 & 0.077 & Yes & 0.8665 & Yes & Definitive $(y=x)$ \\
\hline Olea & Pollen & 0.9 & Yes & 0.974 & 1.452 & Yes & 0.957 & Yes & Definitive $(y=x)$ \\
\hline Caryophyllaceae & Pollen & 0.7 & Yes & 0.981 & -0.137 & Yes & 1.155 & No & Quantitative $(y=m x)$ \\
\hline Rumex acetosella & Pollen & 0.4 & Yes & 0.879 & 0.023 & Yes & 0.898 & Yes & Definitive $(y=x)$ \\
\hline Type 8a & NPP & 23.3 & Yes & 0.972 & 1.182 & Yes & 0.906 & Yes & Definitive $(y=x)$ \\
\hline Sordaria & NPP & 14.8 & Yes & 0.904 & 1.173 & Yes & 0.931 & Yes & Definitive $(y=x)$ \\
\hline Type 25 & NPP & 3.7 & Yes & 0.923 & 0.372 & Yes & 0.886 & Yes & Definitive $(y=x)$ \\
\hline Type 303 & NPP & 3.0 & Yes & 0.892 & 0.6252 & Yes & 0.810 & Yes & Definitive $(y=x)$ \\
\hline Type 202 & NPP & 2.3 & Yes & 0.938 & 0.552 & Yes & 0.8573 & Yes & Definitive $(y=x)$ \\
\hline Charcoal & Charcoal & N/A & Yes & 0.963 & -13135 & Yes & 1.045 & Yes & Definitive $(y=x)$ \\
\hline Lycopodium & Lycopodium & $\mathrm{N} / \mathrm{A}$ & Yes & 0.982 & -7.580 & Yes & 1.056 & Yes & Definitive $(y=x)$ \\
\hline
\end{tabular}


619 APPENDIX 1. Pollen preparation protocol, including HF and dense media options.

620 Please refer to Figure 3 for an overview.

621

622

623

624

625

626

627

628

629

630

631

632

633

634

635

636

637

638

639

640

641

642

643

644

645

646

647

648

1. Volumetric sampling and the addition of Lycopodium. Plastic syringes with a $1 \mathrm{~cm}^{3}$ volume were used to measure out each individual sample. The samples were transferred to large $(50 \mathrm{~mL})$ centrifuge tubes and a single Lycopodium tablet was added to each sample. The addition of the Lycopodium, an exotic marker grain, to a known volume of sediment enables the absolute abundance of pollen grains to be determined (Stockmarr, 1971).

2. Removal of carbonates by acid digestion $(\mathbf{H C l}) .10 \mathrm{ml}$ of $10 \% \mathrm{v} / \mathrm{v}$ Hydrochloric acid $(\mathrm{HCl})$ was slowly added to each sample, and stirred using a glass stirring rod. The samples were placed in the waterbath at $90^{\circ} \mathrm{C}$ for 20 minutes. They were then centrifuged in a Heraeus Megafuge 16 at 4500 rpm for three minutes. After the supernatant had been decanted they were mixed with deionised water and centrifuged again.

3. Removal of humic acids by alkali digestion (KOH). $10 \mathrm{ml} 10 \% \mathrm{w} / \mathrm{v} \mathrm{KOH}$ was added to the samples, which were then placed in the water bath at $90^{\circ} \mathrm{C}$ for 10 minutes. The samples were then centrifuged at $4500 \mathrm{rpm}$ for three minutes, and the supernatant was decanted.

4. Removal of coarse plant debris. Approximately $5 \mathrm{ml}$ of water was added to each sample. The samples were then agitated into suspension using the vortex mixer, and washed through 180 micron sieve mesh down a funnel into a clean $50 \mathrm{~mL}$ centrifuge tube. Deionised water was added to balance the samples, and then they were centrifuged at $4500 \mathrm{rpm}$ for three minutes and the supernatant was decanted.

5. Removal of clays and breakdown of products of alkali digestion. The samples were re-suspended in water using the vortex mixture and then centrifuged at $2200 \mathrm{rpm}$ for three minutes. The supernatant was decanted. This step was repeated up to 20 times, until the supernatant was clear.

6. a) Removal of silicates using HF. The samples were suspended in $5 \mathrm{ml}$ of $10 \% \mathrm{HCl}$, to ensure the sample is entirely free from carbonates and to acidify 
the sample. They were stirred and then centrifuged at $4500 \mathrm{rpm}$ for 3 minutes, after which the supernatant was decanted. Working in a HFprepared fume cupboard with environmental scrubbers and wearing suitable safety equipment (face mask, environmental hazard suit, rubber boots, double nitrile gloves) $3 \mathrm{ml}$ of HF was added, and the samples were stirred careful with polypropylene stirring rods. They were then placed in a hot water bath for 20 minutes, and the stirring rods were used to check for remaining grittiness in the tube. The samples were heated until all silica had been dissolved. The supernatant was decanted and $5 \mathrm{ml} 10 \% \mathrm{HCl}$ was added to the pellet and stirred. The tubes were placed back into the hot water bath for 15 minutes to remove any silicofluorides. They were centrifuged at $4500 \mathrm{rpm}$ for three minutes, decanted, and topped up with deionised water. This latter step was repeated three times.

662

b) Density separation using SPT. A suitable volume of SPT (sodium polytungstate) solution was prepared to a specific gravity between 1.88-1.91 $\mathrm{g} / \mathrm{cm}^{3}$, allowing for $10 \mathrm{ml}$ per sample. The software LSTCalc (http://www.polytungstate.co.uk/lstcalc.html) was used to help determine the correct volume of water to add to the starting volume of SPT of known specific gravity. The samples were suspended in $5 \mathrm{ml} \mathrm{10 \%} \mathrm{HCl}$ to acidify the sample, which aids with the density separation. They were mixed and centrifuged at $4500 \mathrm{rpm}$ for three minutes, and the supernatant was decanted fully, removing as much water as possible so as not to affect the density of the SPT. $10 \mathrm{ml}$ of the prepared SPT solution was added to each tube. The tubes were capped and mixed using the vortex mixer for at least 20 seconds each. The samples were centrifuged at $1800 \mathrm{rpm}$ for 20 minutes. They were then left overnight to further aid separation; this option allows for material in suspension in the supernatant to float to the top, making it easier to see and decant the floating organic material. The supernatant of each sample was poured into a new centrifuge tube, topped up with deionised water to within 5 $\mathrm{ml}$ of the top of the tube (reducing the overall density to around 1.15-1.2 $\mathrm{g} / \mathrm{cm}^{3}$ ), capped, and mixed by performing 8-10 inversions by hand. The centrifuge tubes containing the supernatant were then centrifuged at 4500 rpm for three minutes. The supernatant was decanted into a wash bottle for 
later recycling of SPT. The samples were topped up with deionised water and centrifuged and decanted again twice.

7. Removal of cellulose by acetolysis. The acetolysis mixture was prepared by mixing nine parts of acetic anhydride with one part concentrated sulphuric acid. The samples were suspended in $5 \mathrm{ml}$ of glacial acetic acid, to dehydrate the sample; they were centrifuged at $4500 \mathrm{rpm}$ for three minutes, and the supernatant was decanted. $5 \mathrm{ml}$ of the acetolysis mixture was added to each tube. The samples were then placed in the water bath at $90^{\circ} \mathrm{C}$ for two minutes. They were centrifuged at $4500 \mathrm{rpm}$ for two minutes and decanted. 5 $\mathrm{ml}$ of glacial acetic was added; the samples were stirred, centrifuged at 4500 $\mathrm{rpm}$ for three minutes, and decanted. They were suspended in $5 \mathrm{ml} \mathrm{10 \%} \mathrm{KOH}$ to neutralise the acid, stirred, centrifuged at $4500 \mathrm{rpm}$ for three minutes and then decanted. Finally they were suspended in $5 \mathrm{ml}$ of deionised water, centrifuged at $4500 \mathrm{rpm}$ for three minutes, and the supernatant was decanted.

8. Alcoholic dehydration. After suspending the samples in $5 \mathrm{ml}$ of ethanol, they were mixed and centrifuged for three minutes at $4500 \mathrm{rpm}$ and then decanted. They were then suspended in $1 \mathrm{ml}$ of tert-butyl alcohol (TBA) and centrifuged at $4500 \mathrm{rpm}$, and then decanted. $1 \mathrm{ml}$ TBA was added to each sample; they were mixed, and then transferred to a glass vial with a pasteur pipette. The samples were centrifuged at $4500 \mathrm{rpm}$ for three minutes, and then decanted. Approximately $0.5 \mathrm{ml}$ of silicone oil was added to the samples, and the vials were topped with cotton wool. The samples were left for two days to allow the remaining TBA to evaporate.

9. Making slides. Where necessary, additional silicone oil was added to the samples, which were stirred with a microspatula. A small drop of the sample was placed in the middle of the slide, and a glass cover slip was slowly placed over the top. A seeker was used to apply gentle pressure to the slip, allowing the sample to spread out. The slip was sealed with clear nail varnish, and labelled. 


\begin{tabular}{|c|c|c|c|c|c|c|c|c|c|c|c|c|c|c|c|c|}
\hline \multirow{2}{*}{\multicolumn{2}{|c|}{ Sample }} & \multicolumn{3}{|c|}{ \% Quercus evergreen } & \multicolumn{3}{|c|}{ \% Quercus deciduous } & \multicolumn{3}{|c|}{ \%Cedrus } & \multicolumn{3}{|c|}{ \% Poaceae } & \multicolumn{3}{|c|}{ \% Cupressaceae } \\
\hline & & Upper 95\% & Mid point & Lower 95\% & Upper 95\% & Mid point $L$ & Lower 95\% & Upper 95\% & Mid point & Lower 95\% & Upper $95 \%$ & Mid point & Lower 95\% & Upper $95 \%$ & Mid point & Lower 95\% \\
\hline & $\mathrm{HF}$ & 40.55 & 35.06 & 29.95 & 15.76 & 11.69 & 8.56 & 27.04 & 22.08 & 17.81 & 11.71 & 8.12 & 5.56 & 8.99 & 5.81 & 3.70 \\
\hline & SPT & 38.04 & 32.56 & 27.51 & 15.00 & 10.96 & 7.91 & 31.84 & 26.58 & 21.91 & 15.00 & 10.96 & 7.91 & 8.06 & 4.98 & 3.04 \\
\hline \multirow{2}{*}{$\mathrm{SA} 2$} & HF & 24.89 & 20.00 & 15.87 & 6.03 & 3.33 & 1.82 & 26.67 & 21.67 & 17.38 & 16.17 & 12.00 & 8.80 & 15.79 & 11.67 & 8.51 \\
\hline & SPT & 23.95 & 19.14 & 15.11 & 6.79 & 3.96 & 2.28 & 24.30 & 19.47 & 15.41 & 14.53 & 10.56 & 7.58 & 16.75 & 12.54 & 9.27 \\
\hline \multirow{2}{*}{ SA 3} & $\mathrm{HF}$ & 29.19 & 24.10 & 19.66 & 8.30 & 5.21 & 3.23 & 32.27 & 27.04 & 22.37 & 6.71 & 3.91 & 2.25 & 18.34 & 14.01 & 10.57 \\
\hline & SPT & 28.09 & 23.00 & 18.60 & 7.27 & 4.33 & 2.55 & 35.07 & 29.67 & 24.78 & 7.68 & 4.67 & 2.80 & 20.94 & 16.33 & 12.58 \\
\hline \multirow{2}{*}{ SA 4} & $\mathrm{HF}$ & 25.44 & 20.53 & 16.36 & 8.43 & 5.30 & 3.29 & 24.73 & 19.87 & 15.76 & 5.57 & 2.98 & 1.58 & 27.91 & 22.85 & 18.47 \\
\hline & SPT & 27.12 & 22.15 & 17.86 & 9.46 & 6.19 & 4.00 & 21.54 & 16.94 & 13.16 & 6.30 & 3.58 & 2.01 & 25.74 & 20.85 & 16.68 \\
\hline \multirow{2}{*}{ SA 5} & HF & 36.67 & 31.23 & 26.26 & 7.25 & 4.32 & 2.54 & 24.81 & 19.93 & 15.81 & 7.25 & 4.32 & 2.54 & 17.59 & 13.29 & 9.91 \\
\hline & SPT & 33.98 & 28.71 & 23.96 & 5.84 & 3.23 & 1.76 & 26.53 & 21.61 & 17.39 & 5.84 & 3.23 & 1.76 & 18.87 & 14.52 & 11.03 \\
\hline \multirow{2}{*}{ SA 6} & HF & 27.81 & 22.80 & 18.46 & 9.85 & 6.51 & 4.26 & 18.69 & 14.33 & 10.85 & 13.98 & 10.10 & 7.21 & 24.00 & 19.22 & 15.20 \\
\hline & SPT & 29.60 & 24.52 & 20.06 & 9.37 & 6.13 & 3.96 & 20.63 & 16.13 & 12.45 & 11.63 & 8.06 & 5.52 & 20.98 & 16.45 & 12.74 \\
\hline \multirow{2}{*}{ SA 7} & HF & 27.12 & 22.15 & 17.86 & 7.11 & 4.23 & 2.49 & 28.85 & 23.78 & 19.36 & 9.08 & 5.86 & 3.74 & 23.65 & 18.89 & 14.91 \\
\hline & SPT & 26.35 & 21.43 & 17.21 & 8.66 & 5.52 & 3.47 & 27.04 & 22.08 & 17.81 & 10.58 & 7.14 & 4.76 & 22.17 & 17.53 & 13.69 \\
\hline \multirow{2}{*}{ SA 8} & HF & 29.37 & 24.38 & 19.99 & 21.70 & 17.19 & 13.45 & 30.35 & 25.31 & 20.86 & 15.18 & 11.25 & 8.24 & 7.57 & 4.67 & 2.85 \\
\hline & SPT & 29.05 & 23.92 & 19.45 & 24.81 & 19.93 & 15.81 & 35.30 & 29.90 & 25.01 & 12.74 & 8.97 & 6.24 & 5.58 & 2.99 & 1.58 \\
\hline \multirow{2}{*}{ SA 9} & $\mathrm{HF}$ & 30.90 & 25.67 & 21.05 & 20.57 & 16.00 & 12.29 & 31.59 & 26.33 & 21.67 & 14.29 & 10.33 & 7.38 & 8.08 & 5.00 & 3.05 \\
\hline & SPT & 31.38 & 26.27 & 21.72 & 24.35 & 19.62 & 15.62 & 27.72 & 22.78 & 18.50 & 11.05 & 7.59 & 5.16 & 7.51 & 4.56 & 2.74 \\
\hline \multirow{2}{*}{ SA 10} & HF & 39.45 & 34.07 & 29.07 & 14.26 & 10.41 & 7.51 & 14.61 & 10.73 & 7.78 & 14.26 & 10.41 & 7.51 & 10.62 & 7.23 & 4.87 \\
\hline & SPT & 38.16 & 32.81 & 27.87 & 17.77 & 13.56 & 10.23 & 17.08 & 12.93 & 9.68 & 12.11 & 8.52 & 5.92 & 10.65 & 7.26 & 4.88 \\
\hline \multirow{2}{*}{ CZ1 } & HF & 17.70 & 13.38 & 9.98 & 3.85 & 1.67 & 0.72 & 40.00 & 34.45 & 29.29 & 21.01 & 16.39 & 12.62 & 7.30 & 4.35 & 2.56 \\
\hline & SPT & 15.32 & 11.26 & 8.17 & 4.71 & 2.32 & 1.13 & 41.99 & 36.42 & 31.20 & 22.24 & 17.55 & 13.67 & 5.57 & 2.98 & 1.58 \\
\hline \multirow{2}{*}{ CZ2 } & HF & 7.51 & 4.56 & 2.74 & 3.76 & 1.63 & 0.70 & 38.67 & 33.22 & 28.19 & 25.74 & 20.85 & 16.68 & 11.74 & 8.14 & 5.58 \\
\hline & SPT & 6.38 & 3.63 & 2.04 & 2.87 & 0.99 & 0.34 & 43.87 & 38.28 & 32.99 & 23.95 & 19.14 & 15.11 & 9.97 & 6.60 & 4.31 \\
\hline \multirow[b]{2}{*}{ CZ3 } & HF & 9.82 & 6.49 & 4.24 & 3.74 & 1.62 & 0.70 & 63.81 & 58.44 & 52.87 & 12.45 & 8.77 & 6.09 & 5.87 & 3.25 & 1.77 \\
\hline & SPT & 10.96 & 7.47 & 5.03 & 4.18 & 1.95 & 0.90 & 61.28 & 55.84 & 50.26 & 11.33 & 7.79 & 5.29 & 6.69 & 3.90 & 2.24 \\
\hline & HF & 10.38 & 7.01 & 4.67 & 7.34 & 4.46 & 2.67 & 58.94 & 53.50 & 47.98 & 11.49 & 7.96 & 5.45 & 5.76 & 3.28 & 1.74 \\
\hline CZ2 & SPT & 12.91 & 9.15 & 6.41 & 6.32 & 3.59 & 2.02 & 57.82 & 52.29 & 46.70 & 12.91 & 9.15 & 6.41 & 8.32 & 5.23 & 3.24 \\
\hline$c 75$ & HF & 11.60 & 8.04 & 5.50 & 5.82 & 3.22 & 1.76 & 53.45 & 47.91 & 42.42 & 13.44 & 9.65 & 6.84 & 9.72 & 6.43 & 4.20 \\
\hline CZ25 & SPT & 10.58 & 7.14 & 4.76 & 4.62 & 2.27 & 1.11 & 56.19 & 50.65 & 45.09 & 14.67 & 10.71 & 7.73 & 9.05 & 5.84 & 3.73 \\
\hline & HF & 9.38 & 6.06 & 3.87 & 2.42 & 0.67 & 0.18 & 70.19 & 64.98 & 59.40 & 10.96 & 7.41 & 4.94 & 3.88 & 1.68 & 0.72 \\
\hline C26 & SPT & 7.18 & 4.28 & 2.52 & 3.79 & 1.64 & 0.70 & 66.81 & 61.51 & 55.93 & 13.74 & 9.87 & 7.00 & 5.11 & 2.63 & 1.34 \\
\hline & HF & 10.99 & 7.49 & 5.04 & 2.83 & 0.98 & 0.33 & 69.64 & 64.50 & 58.99 & 10.23 & 6.84 & 4.52 & 7.11 & 4.23 & 2.49 \\
\hline C27 & SPT & 9.11 & 5.88 & 3.75 & 3.77 & 1.63 & 0.70 & 72.33 & 67.32 & 61.88 & 8.32 & 5.23 & 3.24 & 6.32 & 3.59 & 2.02 \\
\hline CZ8 & HF & 9.79 & 6.47 & 4.23 & 2.83 & 0.98 & 0.33 & 47.93 & 42.35 & 36.95 & 13.52 & 9.71 & 6.89 & 4.63 & 2.28 & 1.11 \\
\hline 028 & SPT & 12.99 & 9.21 & 6.45 & 4.24 & 1.97 & 0.91 & 46.40 & 40.79 & 35.41 & 12.24 & 8.55 & 5.90 & 5.95 & 3.29 & 1.80 \\
\hline & HF & 22.81 & 18.09 & 14.17 & 10.68 & 7.21 & 4.81 & 4.22 & 1.97 & 0.90 & 13.74 & 9.87 & 7.00 & 3.78 & 1.64 & 0.70 \\
\hline 629 & SPT & 20.38 & 15.92 & 12.29 & 8.50 & 5.41 & 3.41 & 6.16 & 3.50 & 1.97 & 14.75 & 10.83 & 7.85 & 2.77 & 0.96 & 0.33 \\
\hline & HF & 5.87 & 3.25 & 1.77 & 2.82 & 0.97 & 0.33 & 4.62 & 2.27 & 1.11 & 24.27 & 19.48 & 15.44 & 7.88 & 4.87 & 2.97 \\
\hline CZ 10 & SPT & 8.22 & 5.16 & 3.20 & 2.32 & 0.65 & 0.18 & 3.72 & 1.61 & 0.69 & 22.73 & 18.06 & 14.18 & 9.37 & 6.13 & 3.96 \\
\hline
\end{tabular}




\begin{tabular}{|c|c|c|c|c|c|c|c|c|c|c|c|c|c|c|c|c|}
\hline \multirow{2}{*}{$\mathrm{AA} 1$} & HF & 20.70 & 16.18 & 12.49 & 2.82 & 0.97 & 0.33 & 42.73 & 37.22 & 32.01 & 25.92 & 21.04 & 16.86 & 3.73 & 1.62 & 0.69 \\
\hline & SPT & 24.00 & 19.22 & 15.20 & 1.82 & 0.33 & 0.06 & 38.34 & 32.90 & 27.88 & 28.50 & 23.45 & 19.06 & 4.63 & 2.28 & 1.11 \\
\hline \multirow{2}{*}{ AA 2} & $\mathrm{HF}$ & 15.79 & 11.67 & 8.51 & 6.03 & 3.33 & 1.82 & 42.26 & 36.67 & 31.41 & 22.02 & 17.33 & 13.47 & 3.84 & 1.78 & 0.71 \\
\hline & SPT & 17.56 & 13.31 & 9.97 & 7.48 & 4.55 & 2.73 & 39.22 & 33.77 & 28.71 & 18.99 & 14.61 & 11.10 & 5.87 & 3.25 & 1.77 \\
\hline \multirow{2}{*}{ AA 3} & HF & 33.62 & 28.34 & 23.59 & 2.83 & 0.98 & 0.33 & 34.98 & 29.64 & 24.81 & 11.74 & 8.14 & 5.58 & 10.99 & 7.49 & 5.04 \\
\hline & SPT & 31.74 & 26.49 & 21.83 & 4.27 & 1.99 & 0.91 & 38.26 & 32.78 & 27.73 & 10.78 & 7.28 & 4.86 & 9.22 & 5.96 & 3.80 \\
\hline \multirow{2}{*}{ AA 4} & HF & 22.87 & 18.18 & 14.28 & 7.88 & 4.87 & 2.97 & 18.99 & 14.61 & 11.10 & 17.20 & 12.99 & 9.68 & 7.88 & 4.87 & 2.97 \\
\hline & SPT & 20.90 & 16.34 & 12.62 & 6.73 & 3.92 & 2.26 & 21.60 & 16.99 & 13.20 & 19.47 & 15.03 & 11.46 & 9.11 & 5.88 & 3.75 \\
\hline \multirow{2}{*}{ AA 5} & $\mathrm{HF}$ & 18.57 & 14.19 & 10.71 & 5.97 & 3.30 & 1.80 & 36.78 & 31.35 & 26.39 & 9.59 & 6.27 & 4.05 & 1.85 & 0.33 & 0.06 \\
\hline & SPT & 16.48 & 12.34 & 9.12 & 7.88 & 4.87 & 2.97 & 33.52 & 28.25 & 23.51 & 7.88 & 4.87 & 2.97 & 2.34 & 0.65 & 0.18 \\
\hline \multirow{2}{*}{ AA 6} & HF & 17.15 & 12.94 & 9.65 & 4.60 & 2.27 & 1.10 & 36.10 & 30.74 & 25.86 & 20.35 & 15.86 & 12.21 & 9.40 & 6.15 & 3.97 \\
\hline & SPT & 19.68 & 15.29 & 11.73 & 6.95 & 4.14 & 2.44 & 33.90 & 28.66 & 23.94 & 21.42 & 16.88 & 13.14 & 7.34 & 4.46 & 2.67 \\
\hline \multirow{2}{*}{ AA7 } & $\mathrm{HF}$ & 29.44 & 24.35 & 19.89 & 7.88 & 4.87 & 2.97 & 5.87 & 3.25 & 1.77 & 12.45 & 8.77 & 6.09 & 2.34 & 0.75 & 0.18 \\
\hline & SPT & 32.29 & 27.00 & 22.29 & 9.68 & 6.33 & 4.09 & 7.68 & 4.67 & 2.80 & 12.40 & 8.67 & 5.98 & 3.84 & 1.67 & 0.71 \\
\hline \multirow{2}{*}{ AA 8} & HF & 20.68 & 14.29 & 9.63 & 13.13 & 7.79 & 4.51 & 46.19 & 38.31 & 31.01 & 20.68 & 14.29 & 9.63 & 6.49 & 2.60 & 1.01 \\
\hline & SPT & 18.82 & 12.58 & 8.21 & 11.76 & 6.62 & 3.64 & 43.00 & 35.10 & 27.94 & 24.03 & 17.22 & 12.03 & 6.61 & 2.65 & 1.03 \\
\hline \multirow{2}{*}{ AA 9} & $\mathrm{HF}$ & 19.48 & 15.00 & 11.40 & 8.08 & 5.00 & 3.05 & 51.32 & 45.67 & 40.12 & 6.86 & 4.00 & 2.30 & 3.84 & 1.67 & 0.71 \\
\hline & SPT & 16.54 & 12.33 & 9.08 & 6.86 & 4.00 & 2.30 & 53.64 & 48.00 & 42.41 & 5.60 & 3.00 & 1.59 & 2.40 & 0.77 & 0.18 \\
\hline \multirow{2}{*}{ AA 10} & $\mathrm{HF}$ & 27.03 & 22.04 & 17.74 & 5.95 & 3.29 & 1.80 & 61.39 & 55.92 & 50.30 & 2.37 & 0.66 & 0.18 & 1.84 & 0.33 & 0.06 \\
\hline & SPT & 2580 & 20.86 & 16.66 & 763 & 4.64 & 278 & 58.86 & 53.31 & 47.68 & 3.36 & 132 & 0.52 & 3.36 & 132 & 0.52 \\
\hline
\end{tabular}


715 Figure 1: The location of the three sites: Sidi Ali, Col du Zad and Aguelmam Azougagh (AA), indicated by the star, the square and 716 the circle, respectively.
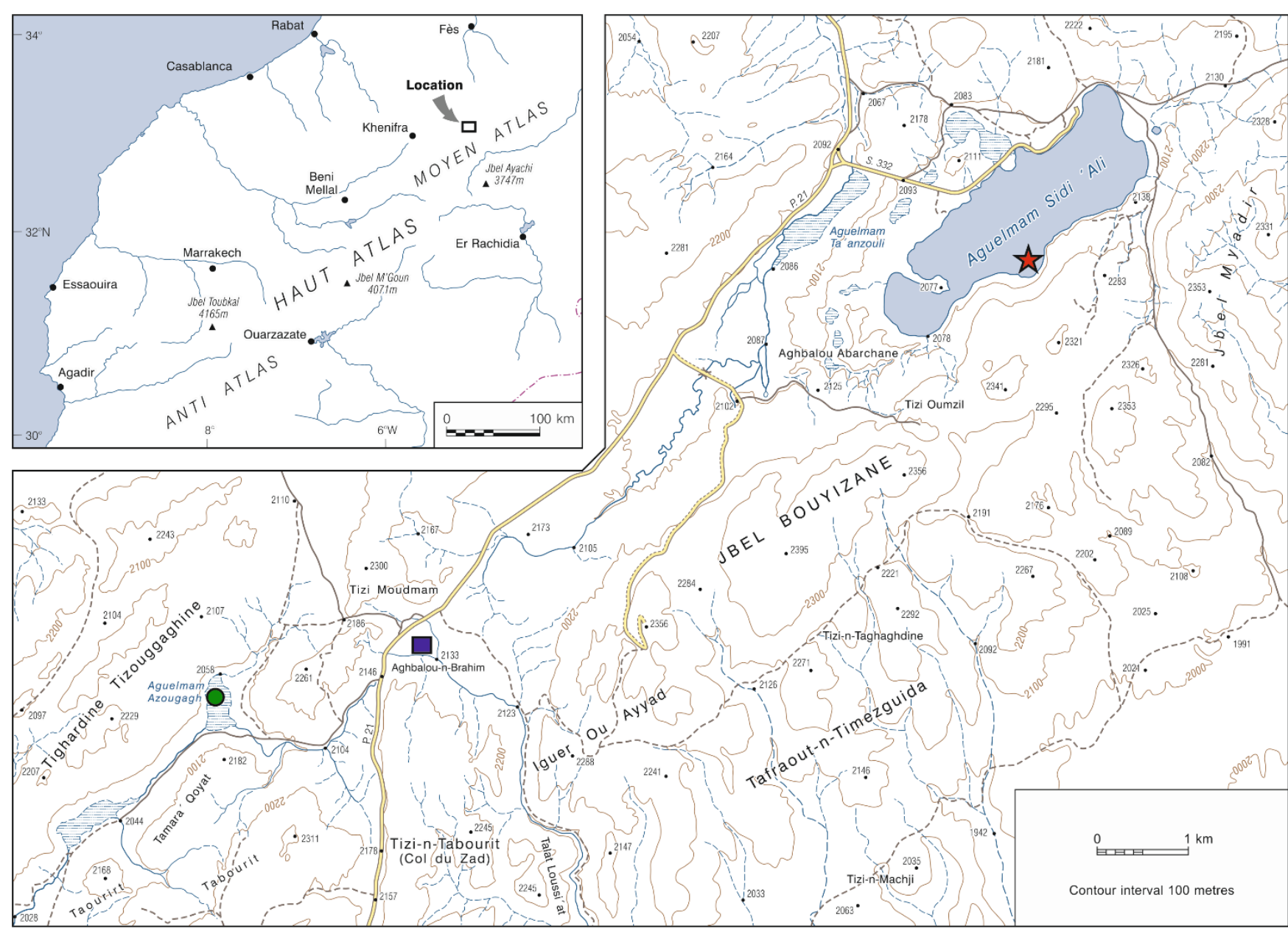
718 Figure 2: Photographs of the three sites: a) Lake Sidi Ali; b) Col du Zad; c) 719 Aguelmam Azougagh.

720

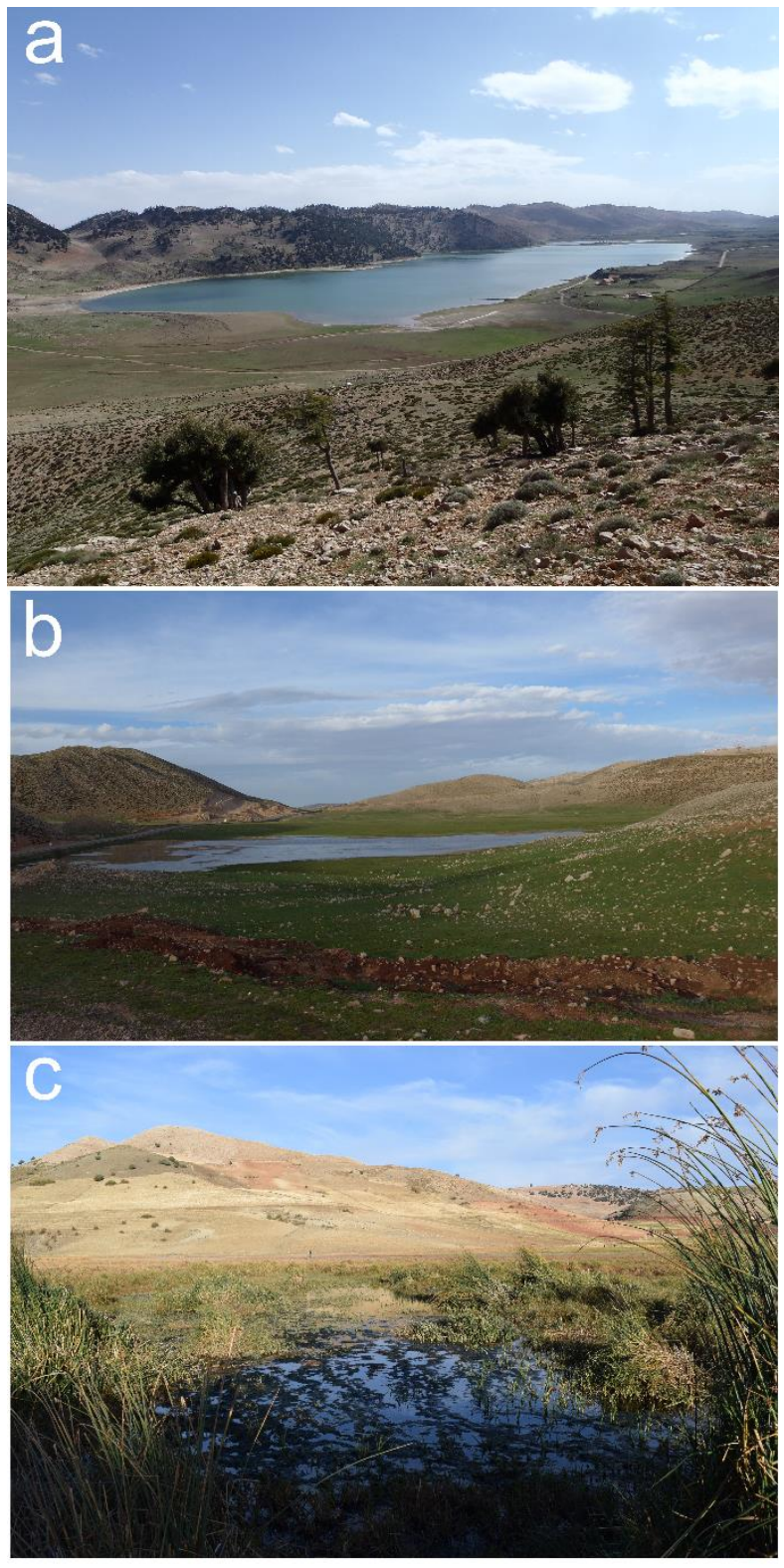

721 
722 Figure 3: A summary of the preparation protocol used for the pollen, NPP and 723 charcoal samples.

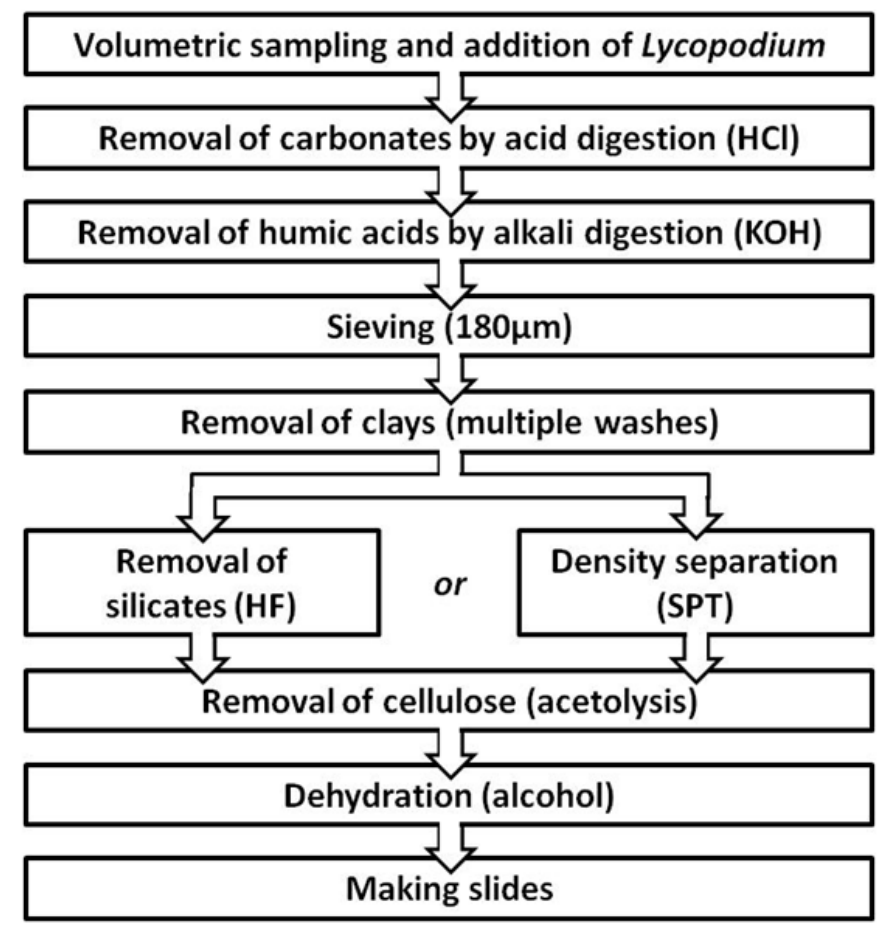


725 Figure 4: Diagrams showing the pollen, fungal spore and charcoal counts for: a) Lake Sidi Ali, b) Col du Zad, and c) Aguelmam 726 Azougagh.
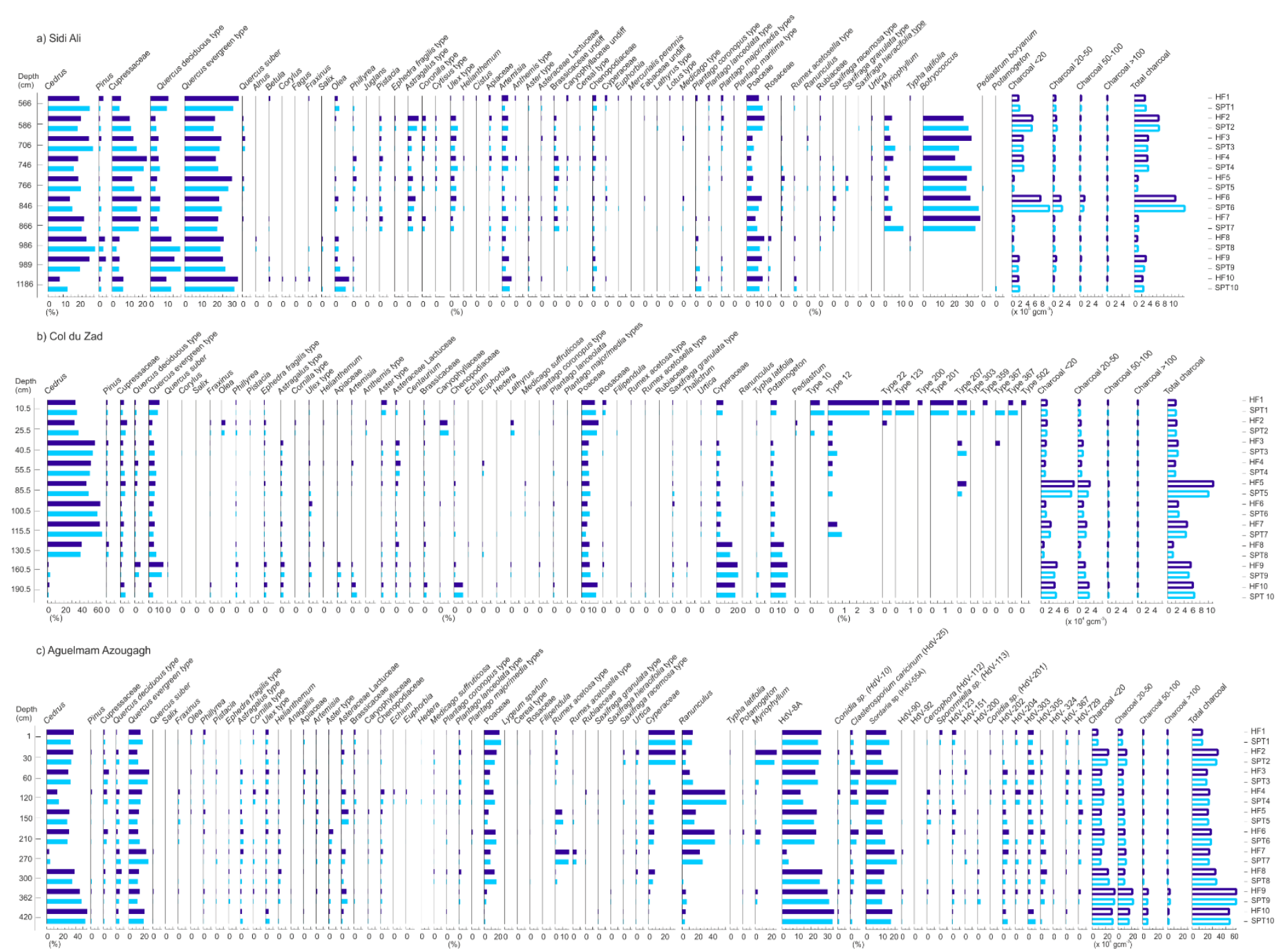
728 Figure 5: Linear regressions for the one-on-one statistics. The black dashed line 729 indicates the initial linear regression $(y=m x+c)$; the solid red line indicates the linear 730 regression that was refit so that $\mathrm{y}=\mathrm{mx}$.

731
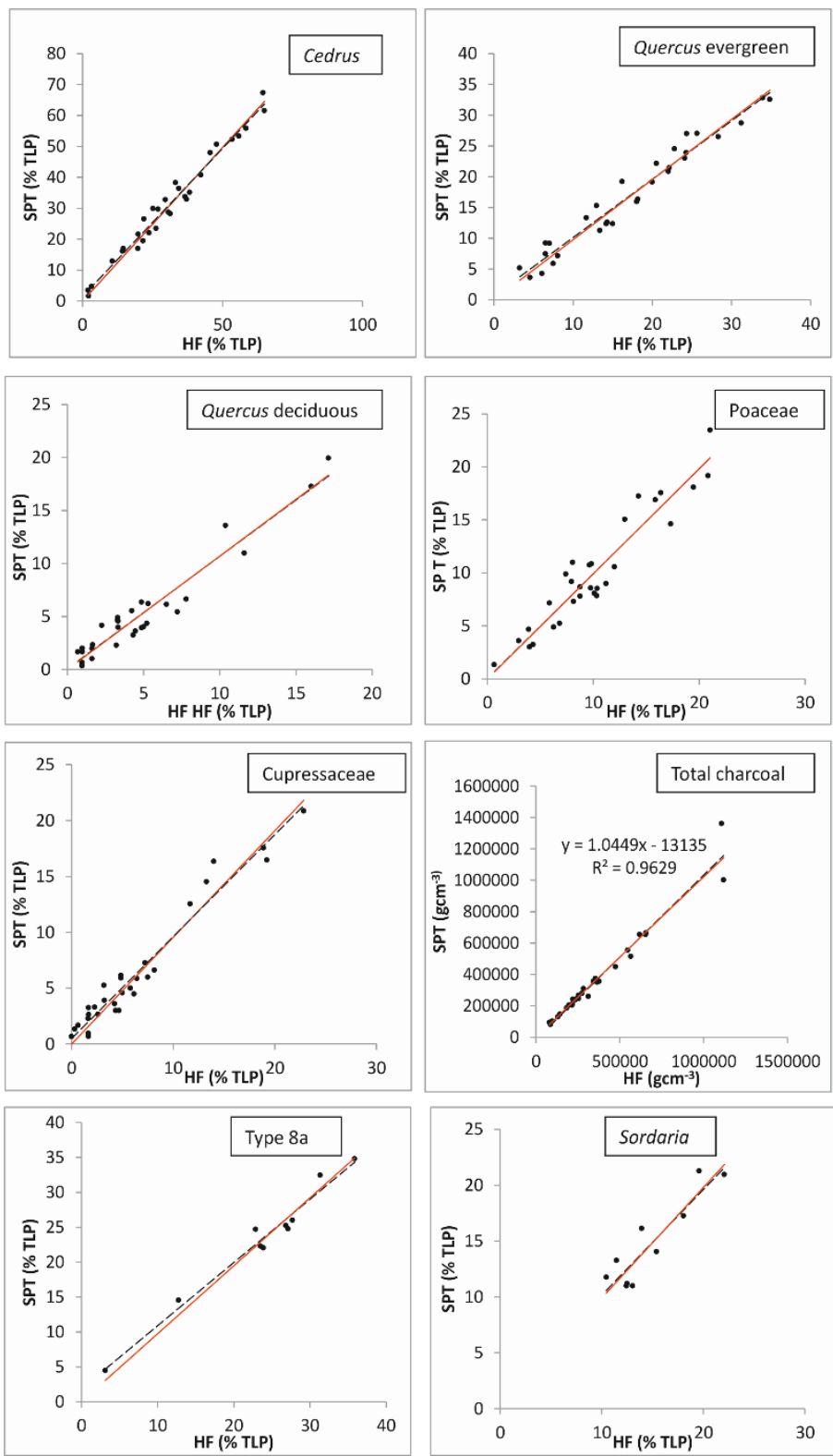
733 Figure 6: Images of the slides prepared for all three sites, using the two separate 734 preparation methods. 1a - Sidi Ali, SPT; 1 b - Sidi Ali, HF; 2a - Col du Zad, SPT; 2b 735 Col du Zad, HF; 3a - Aguelmam Azougagh, SPT; 3b - Aguelmam Azougagh, HF.
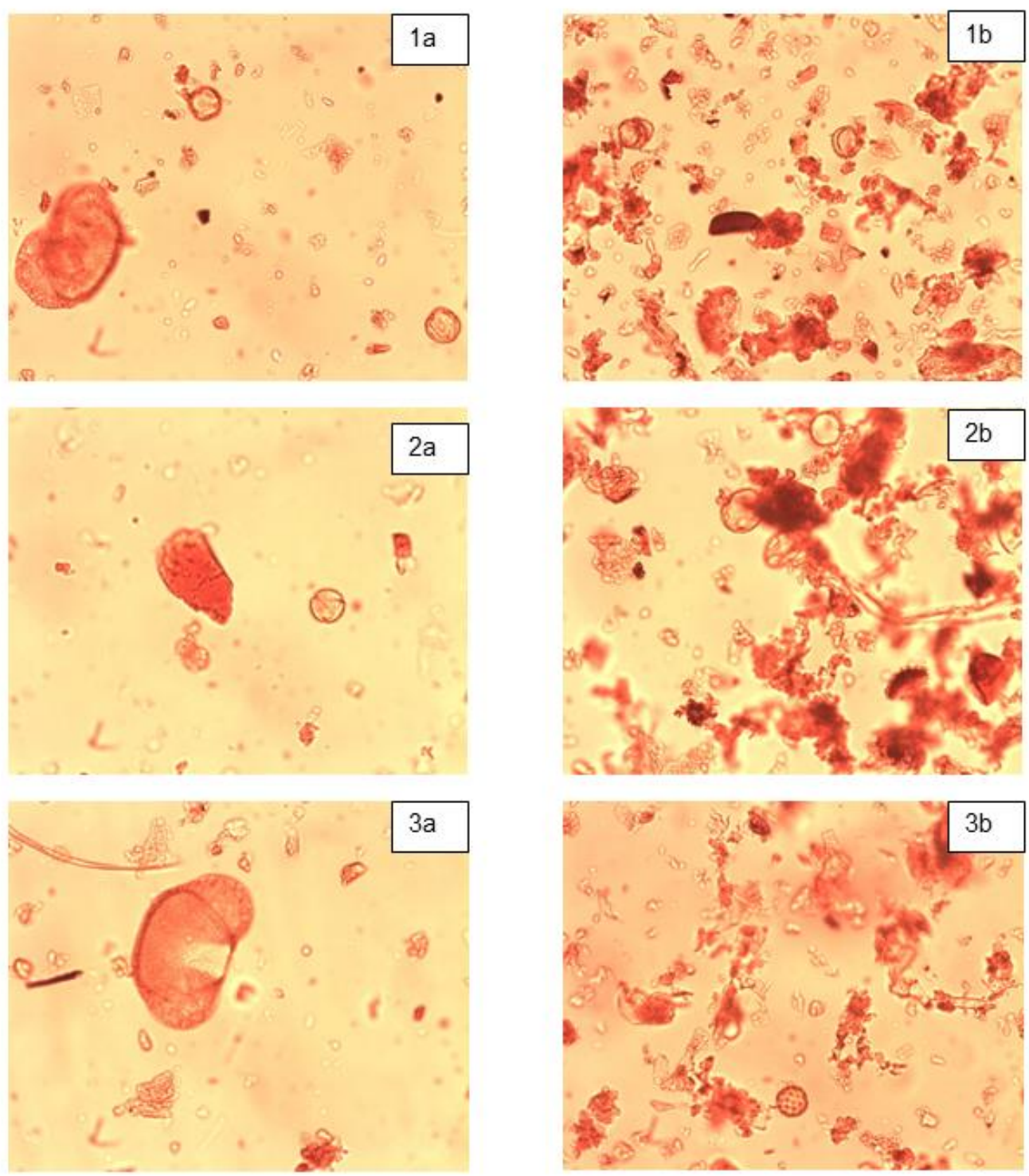